\title{
BMJ Open Is exercise-based cardiac rehabilitation effective? A systematic review and meta-analysis to re-examine the evidence
}

\author{
Richard Powell, ${ }^{1,2}$ Gordon McGregor, ${ }^{1,3}$ Stuart Ennis, ${ }^{1,4}$ Peter K Kimani, ${ }^{5}$ \\ Martin Underwood ${ }^{2}$
}

To cite: Powell R, McGregor G, Ennis $\mathrm{S}$, et al. Is exercise-based cardiac rehabilitation effective? A systematic review and meta-analysis to re-examine the evidence. BMJ Open 2018;8:e019656. doi:10.1136/ bmjopen-2017-019656

- Prepublication history and additional material for this paper are available online. To view these files, please visit the journal online (http://dx.doi. org/10.1136/bmjopen-2017019656).

Received 18 September 2017 Revised 26 January 2018 Accepted 30 January 2018

Check for updates

${ }^{1}$ Department of Cardiac Rehabilitation, Centre for Exercise \& Health, University Hospitals, Coventry, UK ${ }^{2}$ Warwick Clinical Trials Unit, Warwick Medical School, University of Warwick, Coventry, UK

${ }^{3}$ Faculty of Health and Life Sciences, Coventry University, Coventry, UK

${ }^{4}$ Cardiff Centre for Exercise \& Health, Cardiff Metropolitan University, Cardiff, UK

${ }^{5}$ Statistics and Epidemiology Unit, Warwick Medical School, University of Warwick, Coventry, UK

Correspondence to

Richard Powell;

richard.powell@uhcw.nhs.uk

\section{ABSTRACT}

Objectives To determine the contemporary effectiveness of exercise-based cardiac rehabilitation (CR) in terms of all-cause mortality, cardiovascular mortality and hospital admissions.

Data sources Studies included in or meeting the entry criteria for the 2016 Cochrane review of exercise-based $\mathrm{CR}$ in patients with coronary artery disease.

Study eligibility criteria Randomised controlled trials (RCTs) of exercise-based CR versus a no-exercise control whose participants were recruited after the year 2000.

Study appraisal and synthesis methods Two separate reviewers independently screened the characteristics of studies. One reviewer quality appraised any new studies and assessed their risk of bias using the Cochrane

Collaboration's recommended risk of bias tool. Data were reported as the risk difference $(95 \% \mathrm{Cl})$.

Results We included 22 studies with 4834 participants (mean age 59.5 years, $78.4 \%$ male). We found no differences in outcomes between exercise-based CR and a no-exercise control at their longest follow-up period for: all-cause mortality (19 studies; $n=4194$; risk difference $0.00,95 \% \mathrm{Cl}-0.02$ to $0.01, \mathrm{P}=0.38$ ) or cardiovascular mortality ( 9 studies; $n=1182$; risk difference $-0.01,95 \% C$ -0.02 to $0.01, P=0.25)$. We found a small reduction in hospital admissions of borderline statistical significance (11 studies; $\mathrm{n}=1768$; risk difference $-0.05,95 \% \mathrm{Cl}-0.10$ to $-0.00, \mathrm{P}=0.05$ ).

Conclusions and implications of key findings Our analysis indicates conclusively that the current approach to exercise-based CR has no effect on all-cause mortality or cardiovascular mortality, when compared with a no-exercise control. There may be a small reduction in hospital admissions following exercise-based CR that is unlikely to be clinically important.

PROSPERO registration number CRD42017073616.

\section{BACKGROUND}

Cardiovascular disease is the world's biggest killer, accounting for 15 million deaths in 2015 . $^{1}$

Secondary prevention of coronary artery disease through exercise-based CR in those who have a diagnosis of coronary artery
Strengths and limitations of this study

To our knowledge, this is the first systematic review of exercise-based cardiac rehabilitation (CR) that has pooled data relevant to the current medical management of patients diagnosed with coronary artery disease.

- For analysis, we present the data as the risk difference $(95 \% \mathrm{Cl})$, which ensures all studies reporting data on the outcomes of interest were included.

- This systematic review pools data from studies that deliver an intervention recognised as best practice in exercise-based $\mathrm{CR}$, where multiple approaches, including educational/psychosocial components, as well as the exercise component were used.

- We have not done a de novo quality assessment of $21 / 22$ studies included in this review and instead rely on a previous Cochrane assessment.

- We did not include health-related quality of life as an outcome measure as this is unsuitable for metaanalysis.

disease has the potential to reduce mortality, reduce hospital admissions and increase quality of life. Guidelines internationally endorse the use of exercise-based cardiac rehabilitation (CR) programmes. ${ }^{2-5}$

Typically, exercise-based CR aims to achieve $20-60 \mathrm{~min}$ of moderate intensity continuous exercise, 3-5 times a week, with muscular strength and endurance exercises prescribed in conjunction. ${ }^{6}$ Additionally, most programmes include supplementary education (coronary risk factors and cardiac misconceptions), advice on diet and access to psychological support. ${ }^{2478}$ Typically, exercise-based CR is delivered in a supervised centre-based setting, although home-based programmes are used. ${ }^{9}$

A 2016 Cochrane review (63 studies, $\mathrm{n}=14486$ participants) found benefits of exercise-based CR for patients with 
Table 1 Risk of bias assessment for additional study

\section{Santaularia et $\left.a\right|^{29}$}

\begin{tabular}{|c|c|c|}
\hline Bias & Authors' judgement & Support for judgement \\
\hline $\begin{array}{l}\text { Random sequence } \\
\text { generation (selection } \\
\text { bias) }\end{array}$ & Low risk & $\begin{array}{l}\text { A randomisation list in blocks of } 10 \text { was created by a computer random } \\
\text { number generator. The randomisation list and the allocation of patients to } \\
\text { each group were independently controlled by the Clinical Trials Unit. }\end{array}$ \\
\hline $\begin{array}{l}\text { Allocation concealment } \\
\text { (selection bias) }\end{array}$ & Low risk & $\begin{array}{l}\text { A randomisation list in blocks of } 10 \text { was created by a computer random } \\
\text { number generator. The randomisation list and the allocation of patients to } \\
\text { each group were independently controlled by the Clinical Trials Unit. }\end{array}$ \\
\hline $\begin{array}{l}\text { Blinding of outcome } \\
\text { assessment (detection } \\
\text { bias): all outcomes }\end{array}$ & Low risk & $\begin{array}{l}\text { An independent committee that was blind to the patients' treatment group } \\
\text { assessed the main outcomes. This committee comprised a cardiologist, a } \\
\text { rehabilitation cardiologist and a health information manager, all from different } \\
\text { centres. }\end{array}$ \\
\hline $\begin{array}{l}\text { Incomplete outcome } \\
\text { data (attrition bias): all } \\
\text { outcomes }\end{array}$ & Low risk & There was no loss to follow-up. \\
\hline $\begin{array}{l}\text { Selective reporting } \\
\text { (reporting bias) }\end{array}$ & Low risk & $\begin{array}{l}\text { All outcomes described in the methods were reported in the results. Results } \\
\text { regarding quality of life are presented in supplementary data but were not } \\
\text { required for the current review. }\end{array}$ \\
\hline $\begin{array}{l}\text { Groups balanced at } \\
\text { baseline }\end{array}$ & Low risk & $\begin{array}{l}\text { No significant differences between groups were observed, with the exception } \\
\text { of gender: } 23 \% \text { of the control group were women compared with } 7 \% \text { in the } \\
\text { intervention group }(P=0.049) \text {. }\end{array}$ \\
\hline $\begin{array}{l}\text { Intention-to-treat } \\
\text { analysis conducted }\end{array}$ & High risk & No analysis was conducted. \\
\hline $\begin{array}{l}\text { Groups received same } \\
\text { treatment (apart from the } \\
\text { intervention) }\end{array}$ & Low risk & $\begin{array}{l}\text { Patients assigned to the control group received standard care given at the } \\
\text { hospital. In addition to standard care, patients randomised to the intervention } \\
\text { group. }\end{array}$ \\
\hline
\end{tabular}

coronary artery disease. Both cardiovascular mortality (27 studies, risk ratio (RR) $0.74,95 \%$ CI 0.64 to 0.86 ) and hospital readmissions were reduced (15 studies, RR $0.82,95 \%$ CI 0.70 to 0.96 ), when compared with a no-exercise control. However, in contrast to previous systematic reviews and meta-analyses, there was no significant reduction in risk of reinfarction (36 studies, RR $0.90,95 \%$ CI 0.79 to 1.04 ) or all-cause mortality (47 studies, RR $0.96,95 \%$ CI 0.88 to 1.04$).{ }^{10}$

Over recent decades, the medical management of coronary artery disease has been transformed. The introduction of primary percutaneous coronary intervention has reduced short-term major adverse cardiac events and increased long-term survival. ${ }^{11-14}$ Simultaneously, there have also been widespread advances in secondary preventative medical therapy. This includes the introduction of aspirin and betablockers in the 1980s, ${ }^{15}{ }^{16}$ lipid-lowering statins and ACE inhibitors in the $1990 \mathrm{~s}^{17}{ }^{18}$ and, more recently, the introduction of clopidogrel, a secondary antiplatelet, in 2007. ${ }^{19} 20$ Age-adjusted mortality has decreased substantially in this population. ${ }^{21}$ Systematic reviews and meta-analyses that include data from older studies may not correctly assess the potential effect of exercise-based CR. We hypothesise that previous reviews have overestimated the benefit of exercise-based CR.

\section{OBJECTIVES}

To determine the contemporary effectiveness of exercise-based CR on all-cause mortality, cardiovascular mortality and hospital readmissions in patients with coronary artery disease.

\section{METHODS}

We conducted and reported this meta-analysis in accordance with Preferred Reporting Items for Systematic Reviews and Meta-Analyses. ${ }^{22}$

\section{Search strategy}

To identify relevant studies, we started with the latest Cochrane review of exercise-based CR in patients with coronary artery disease. ${ }^{10}$ Studies identified as 'awaiting assessment' or 'on-going' in this review were revisited to establish whether publication had been reached. To identify any new studies published since the completion of the Cochrane review, an updated search was run on 28 February 2017. This search used the same search strategies as the latest Cochrane review. ${ }^{10}$ We searched Cochrane Central Register of Controlled Trials (online supplementary appendix 1), MEDLINE (Ovid), Embase (Ovid) and CINAHL (EBSCO) databases. This approach allowed us to efficiently identify all relevant studies. Where appropriate, we contacted original authors for clarification of any new included studies. 
Studies 'awaiting assessment' or 'on-going' in the latest Cochrane review that met the review entry criteria

$\mathrm{N}=10$
Titles identified from electronic bibliographies and screened for retrieval (period- July 2014-present) $\mathrm{N}=2,408$

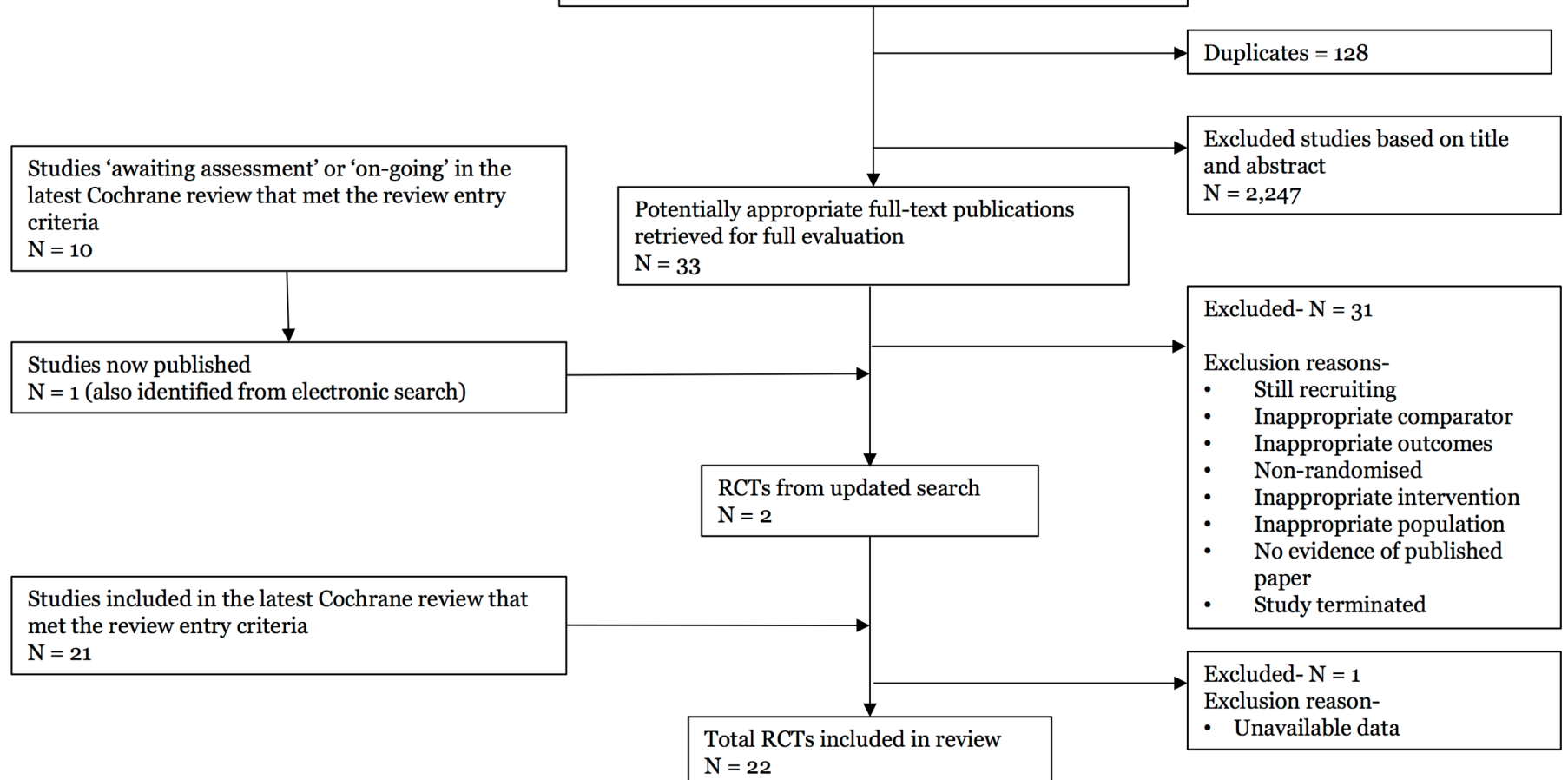

Figure 1 Summary of study selection process. RCTs, randomised controlled trials.

Two separate reviewers (RP and GM) independently screened the characteristics of studies in the latest Cochrane review, studies identified as 'awaiting assessment' or 'on-going' and studies identified in the updated search. Full-text publications were retrieved to allow for further examination and to verify study inclusion. Any discrepancies were resolved by a third reviewer (MU).

\section{Criteria for considering studies}

In 1996, The Task Force on the Management of Acute Myocardial Infarction of the European Society of Cardiology first recommended early (within 2 hours) primary percutaneous interventions in preference to thrombolytic therapy for acute myocardial infarction. ${ }^{23}$ Two years later, guidelines set by the Joint British recommendations on prevention of Coronary Heart Disease in Clinical Practice were published outlining the recommendations for best practice for secondary prevention medical therapies. ${ }^{24}$ Although there have been some changes, notably the introduction of a second antiplatelet agent in the early 2000 s, ${ }^{1920}$ the approach to secondary prevention medical therapies has not changed since then. Allowing time for implementation of these guidelines and recommendations, we identified and included studies whose participants were recruited after the year 2000 to represent a contemporary population engaging in exercise-based CR.

Where there was no indication of recruitment period, the diagnosis and the secondary preventative medical therapy received by participants included in the trial determined the inclusion or exclusion of the study in the analysis.

\section{Types of studies}

We included randomised controlled trials of exercise-based CR compared with a no-exercise control with a minimum follow-up period of 6 months. Data reported at the longest follow-up period were included in the analysis.

\section{Types of participants}

We used the same entry criterion as previous Cochrane reviews:

- people who have had a myocardial infarction or who had undergone revascularisation (coronary artery bypass grafting or percutaneous coronary intervention) or who have angina pectoris or coronary artery disease defined by angiography.

- on optimal secondary preventative medical therapy defined by the Joint British recommendations on prevention of Coronary Heart Disease in Clinical Practice. $^{24}$

- recruited to hospital-based, community-based or home-based CR programmes.

\section{Types of intervention(s)}

Randomised controlled trials consisted of supervised or non-supervised exercise-based CR. The intervention was exercise alone or exercise as part of a comprehensive CR programme (consisting of educational/psychosocial components). 'No exercise control' consisted of standard medical care, including optimal secondary preventative medical therapy, education and advice about diet and exercise, psychosocial support but with no formal exercise intervention. 


\section{Types of outcome measures}

We extracted data on: all-cause mortality, cardiovascular mortality and hospital readmissions. We did not include health-related quality of life as the authors of the 2016 Cochrane review found this unsuitable for meta-analysis.

Data collection, statistical analysis and quality assessment We pooled data using Review Manager V.5.3. ${ }^{25}$ Previous Cochrane reviews have presented the data as individual and pooled risk ratio $(95 \% \mathrm{CI})$. Using risk ratios automatically removed studies with no events in either study arm from the analysis. Nine studies ( $n=936$ participants) reporting on all-cause mortality, cardiovascular mortality or hospital readmissions were excluded from one or more meta-analyses in the 2016 Cochrane review for this reason. We therefore present the data as the risk difference $(95 \% \mathrm{CI})$, which ensures all studies reporting data on the outcomes of interest were included.

We applied a random-effects model to all analyses given the clinical heterogeneity of individual studies. Heterogeneity of included studies were tested statistically using the $\chi^{2}$ test of heterogeneity and $\mathrm{I}^{2}$ statistic. ${ }^{26}$

We did not repeat quality assurance checks already completed by the authors of the Cochrane review. For separate study risk of bias breakdown for these studies, we refer the reader to the existing characteristics of studies. ${ }^{10}$ For studies identified as 'awaiting assessment' or 'on-going' in the latest Cochrane review or in the updated search, we quality appraised these studies and assessed their risk of bias using the Cochrane Collaboration's recommended risk of bias tool. ${ }^{27}$

\section{Assessment of risk of bias in additional included study}

One reviewer (RP) assessed the risk of bias in any additional included studies (table 1). Assessment of three further quality domains as outlined in the latest Cochrane review was also conducted (groups balanced at baseline, intention-to-treat analysis and groups received comparable treatment (except exercise)). A breakdown of the criteria used for assessing these three domains can be found in the latest Cochrane review. Risk of bias assessments were checked by a second reviewer (GM) and any discrepancies were resolved by a third reviewer (MU).

\section{Patient involvement}

No patients were involved in setting the objectives or outcome measures of this review, nor were they involved in the design or implementation. No patients were involved in the analysis or interpretation of the results, nor the writing of any drafts. There are no plans to disseminate the results of the review to participants included in the studies of the review or any relevant patient networks.

\section{RESULTS}

Studies retrieved

Of the 63 studies included in the Cochrane review, 21 studies met our entry criteria. We identified two additional relevant papers not included in the 2016 Cochrane review. ${ }^{28}{ }^{29}$ One was excluded because data for our specific research question were not available in a useable format. ${ }^{28}$ In total, 22 studies $(n=4834$ participants) contributed to the analysis (figure 1). For the study identified from the updated search, ${ }^{29}$ there was a low risk of bias in all eight domains, apart from the intention-totreat analysis, where there was no evidence of this analysis being conducted (table 1 ).

Three studies $(3 / 22 ; 14 \%)$ reported on all three outcomes of interest, 11 studies $(11 / 22 ; 50 \%)$ reported on two outcomes of interest and 8 studies $(8 / 22 ; 36 \%)$ reported on one outcome of interest.

Two studies for all-cause mortality ${ }^{3031}$ and one study for cardiovascular mortality ${ }^{30}$ reported data at varying follow-up periods (6-12 months; >12-36 months; >3 years). Data from these studies were taken at their longest follow-up period. Mean maximum follow-up period was 24.7 months. Maximum follow-up period ranged from 24 weeks to 10 years (table 2 ).

\section{Sample size, gender, age and study origin}

Of our 22 studies, 10 studies were in Europe ${ }^{29-38}$ and 12 from outside of Europe. ${ }^{39-50}$ We included a total of 4834 participants (3788 (78.4\%) males). Four studies included males only, ${ }^{30} 344547$ and one study included women only. ${ }^{51}$ Participants mean age was 59.5 years. The mean age for individual studies ranged from 47.5 to 76.9 years (table 2 ).

\section{Incomplete outcome data}

The majority of trials $(18 / 22 ; 82 \%)$ reported complete follow-up data, regardless of participants who were lost to follow-up or who dropped out. In four studies, outcome data were incomplete for $75(75 / 4,834 ; 1.6 \%)$ participants with no description of withdrawal or dropout. 41474850

\section{Participant diagnosis of coronary artery disease and treatment received}

The diagnosis of participants recruited to the studies was described in the majority of studies $(21 / 22$; $95 \%)$. Thirteen studies enrolled participants with mixed diagnoses, including angina pectoralis or coronary artery disease defined by angiography, myocardial infarction, percutaneous coronary interventions or coronary artery bypass grafts. $^{32} 36-4244$ 46-48 50 Six studies enrolled participants following acute myocardial infarction only, ${ }^{29} 3133344349$ and two studies enrolled participants diagnosed with angina pectoralis (unstable and stable angina) only. ${ }^{30} 35$ It was unclear from one study whether participants following myocardial infarction were included and instead the population was defined as 'patients after coronary artery bypass graft surgery' ${ }^{45}$ (table 2 ).

Six studies recruited participants following percutaneous coronary intervention only 3233354146 and one study recruited participants following coronary artery bypass grafting only. ${ }^{45}$ Twelve studies included participants who had received thrombolysis, percutaneous coronary intervention, coronary artery bypass grafting and/ 


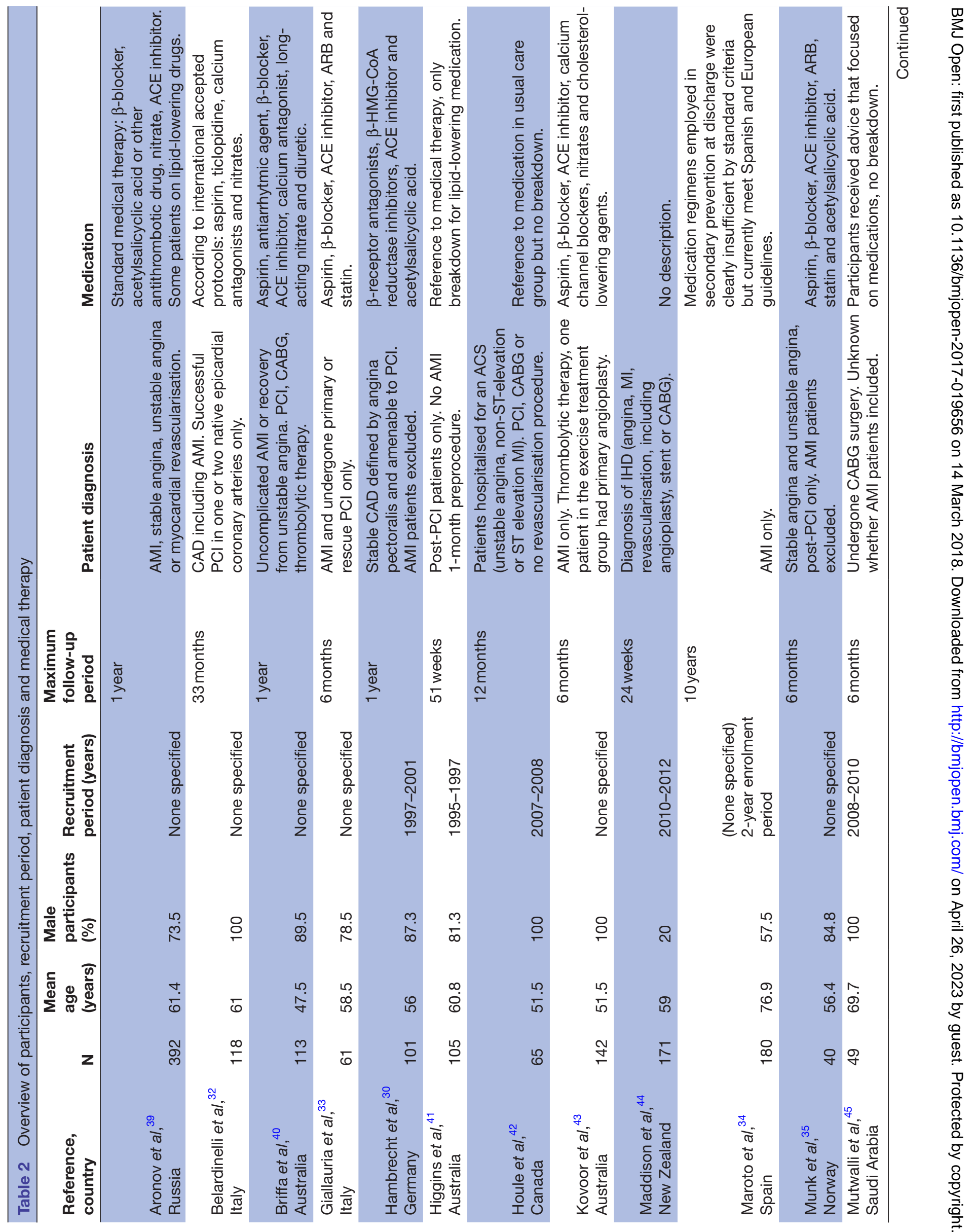




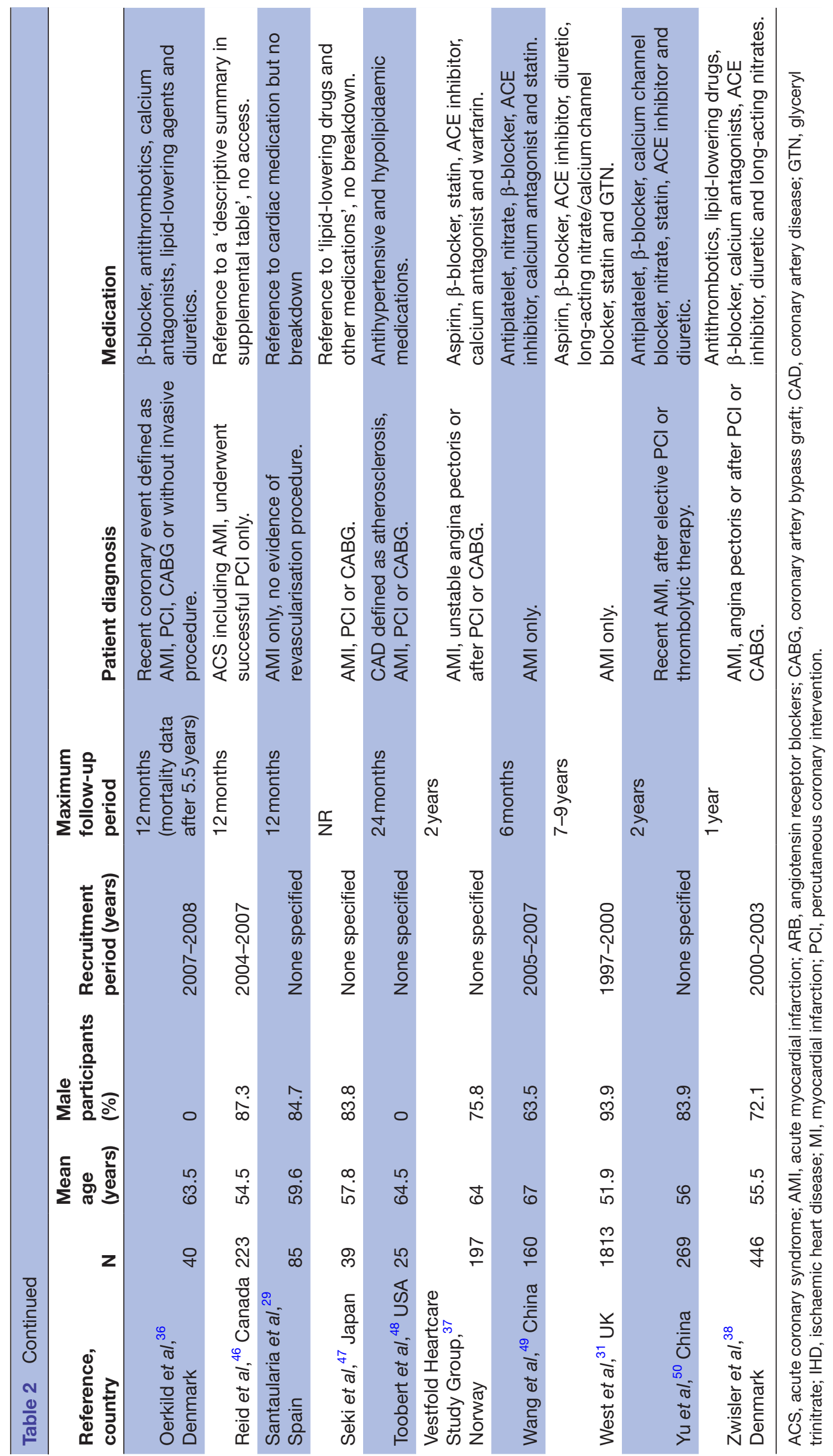

듬 
or no revascularisation procedure. $.^{31} 36-4042-44474850$ Three studies did not provide any breakdown of coronary intervention or surgical procedure received by participants prior to enrolment ${ }^{293449}$ (table 2).

\section{Medication}

A full description and breakdown of the medication received by the participants, comparable with optimal secondary prevention medical therapy defined by the Joint British recommendations on prevention of Coronary Heart Disease in Clinical Practice set in $1998,{ }^{24}$ was provided by 13/22 studies (59\%). $.^{30-33} 35-40434950$ References to coexisting medical therapies were made in $7 / 22$ (32\%), but no breakdowns were provided. ${ }^{29} 34414245-47$ One study referred to the prescription of antihypertensive and hypolipidaemic medications without reference to other recommended medications. ${ }^{48}$ One study failed to provide any description or breakdown of coexisting medical therapies ${ }^{44}$ (table 2 ).

\section{Clearly defined recruitment period}

Seven studies $(7 / 22 ; 32 \%)$ were explicit that they recruited participants after the year 2000. ${ }^{36} 384244-4649$ In three studies, participants were recruited either just before or during the year $2000 .^{30} 3141$ Due to participant diagnosis, treatment received and coexisting medical therapies, it was agreed by all reviewers to include these studies.

The remaining 12 studies failed to provide a recruitment period. Following further examination of the full papers, due to adequate description of patient diagnosis, treatment received and coexisting medical therapies, it was agreed by all reviewers to include these studies (table 2).

\section{Content of the interventions}

The content of the interventions tested was heterogeneous with multiple approaches being adopted. Sixteen studies $(16 / 22 ; 73 \%)$ compared exercise in combination with other therapies (education and psychosocial management), while six studies compared exercise as a stand-alone intervention, against a no-exercise control. The exercise component alone varied considerably with respect to setting, training modality, duration, session length, frequency and intensity (table 3 ).

\section{Overall effects of interventions \\ All-cause mortality}

Nineteen studies ( $\mathrm{n}=4194$ participants) reported all-cause mortality (figure 2). There was no difference between groups at their longest follow-up (risk difference $=0.00$, $95 \% \mathrm{CI}-0.02$ to $0.01, \mathrm{P}=0.38$ ). There was no evidence of statistical heterogeneity across trials $(\mathrm{P}$ value $=0.91$, $\left.\mathrm{I}^{2}=0 \%\right)$.

\section{Cardiovascular mortality}

Nine studies ( $\mathrm{n}=1182$ participants) reported cardiovascular mortality (figure 3 ). There was no difference between groups at their longest follow-up (risk difference $=-0.01,95 \%$ CI -0.02 to $0.01, \mathrm{P}=0.25)$. There was no evidence of statistical heterogeneity across trials $(\mathrm{P}$ value $=0.44, \mathrm{I}^{2}=0 \%$ ).

\section{Hospital admissions}

Eleven studies ( $\mathrm{n}=1768$ participants) reported on proportion with one or more hospital admissions (figure 4). There was a reduction of borderline statistical significance (risk difference $=-0.05,95 \%$ CI -0.10 to -0.00 , $\mathrm{P}=0.05)$. There was evidence of statistical heterogeneity across trials $\left(\mathrm{P}\right.$ value $\left.=0.002, \mathrm{I}^{2}=64 \%\right)$.

\section{DISCUSSION}

The effectiveness of exercise-based CR in patients with coronary artery disease has been determined by Cochrane systematic reviews and meta-analyses, providing clinicians and academics with the highest level of evidence over the last 17 years. ${ }^{10} 5253$ The latest Cochrane review, conducted in 2016, found benefits of exercise-based CR in terms of reduced cardiovascular mortality and hospital admissions, but unlike previous Cochrane reviews, found no effect on all-cause mortality. ${ }^{10}$ We identified that data from studies included in this review dated back as far as $1975 .^{54}$ By including such historical data, this Cochrane review may not be correctly assessing the potential effect of contemporary exercise-based CR.

The current review aimed to assess the effect of exercise-based CR in the era of improved reperfusion strategies and simultaneous advances in pharmacological management, by only including studies whose participants were recruited after the year 2000. The majority of interventions tested in the 22 included trials (table 3) delivered an intervention recognised as best practice in exercise-based CR, where multiple approaches, including educational/psychosocial components, as well as the exercise component were used..$^{238}$ The interventions were tested against a no exercise control consisting of educational and psychosocial components alone (table 3).

The current analyses demonstrated no improvement in all-cause mortality from participation in exercise-based CR: the risk difference was 0.00 (95\% CI -0.02 to 0.01 ). The largest trial included in our analysis, the UK-based Rehabilitation after myocardial infarction trial (RAMIT) trial, sought to show a $20 \%$ reduction in relative risk based on an $11 \%$ mortality, that is, a $2.2 \%$ risk difference. ${ }^{24}$ The limits of the $95 \%$ CI for the effect size in our analysis do not include the RAMIT trial's prespecified clinically important difference. We therefore conclude that it is extremely unlikely that there is a worthwhile benefit from exercise-based CR on all-cause mortality. Furthermore, it is unlikely that future trials of similar interventions and populations will change this conclusion. This is supported by a recent meta-analysis that included participants with other forms of atherosclerotic cardiovascular disease, that is, peripheral artery disease, ischaemic cerebrovascular accidents, diabetes and hypertension. They too found a zero effect on all-cause mortality (relative risk $1.00,95 \%$ CI 0.88 to 1.14$).{ }^{55}$ With the mean follow-up 


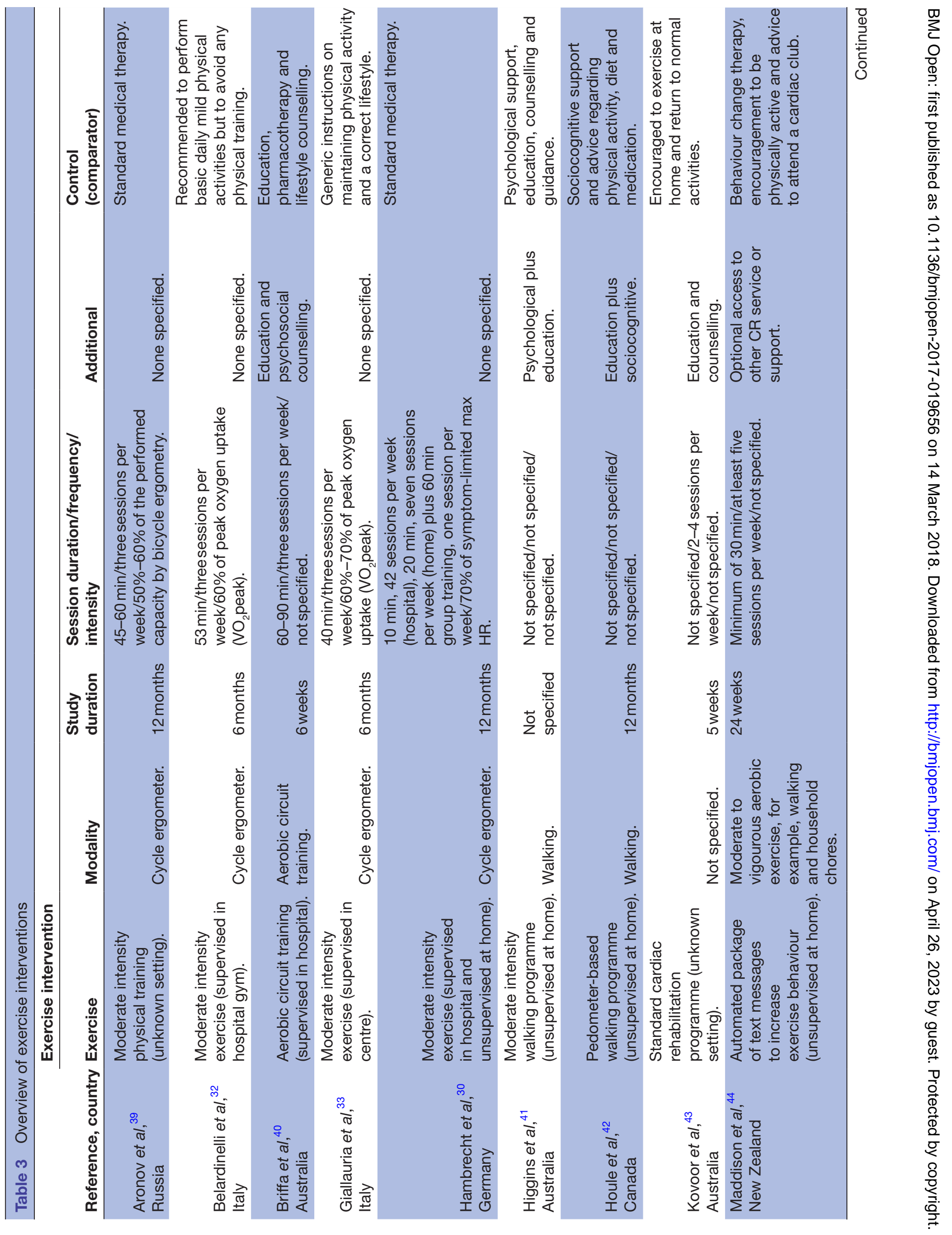




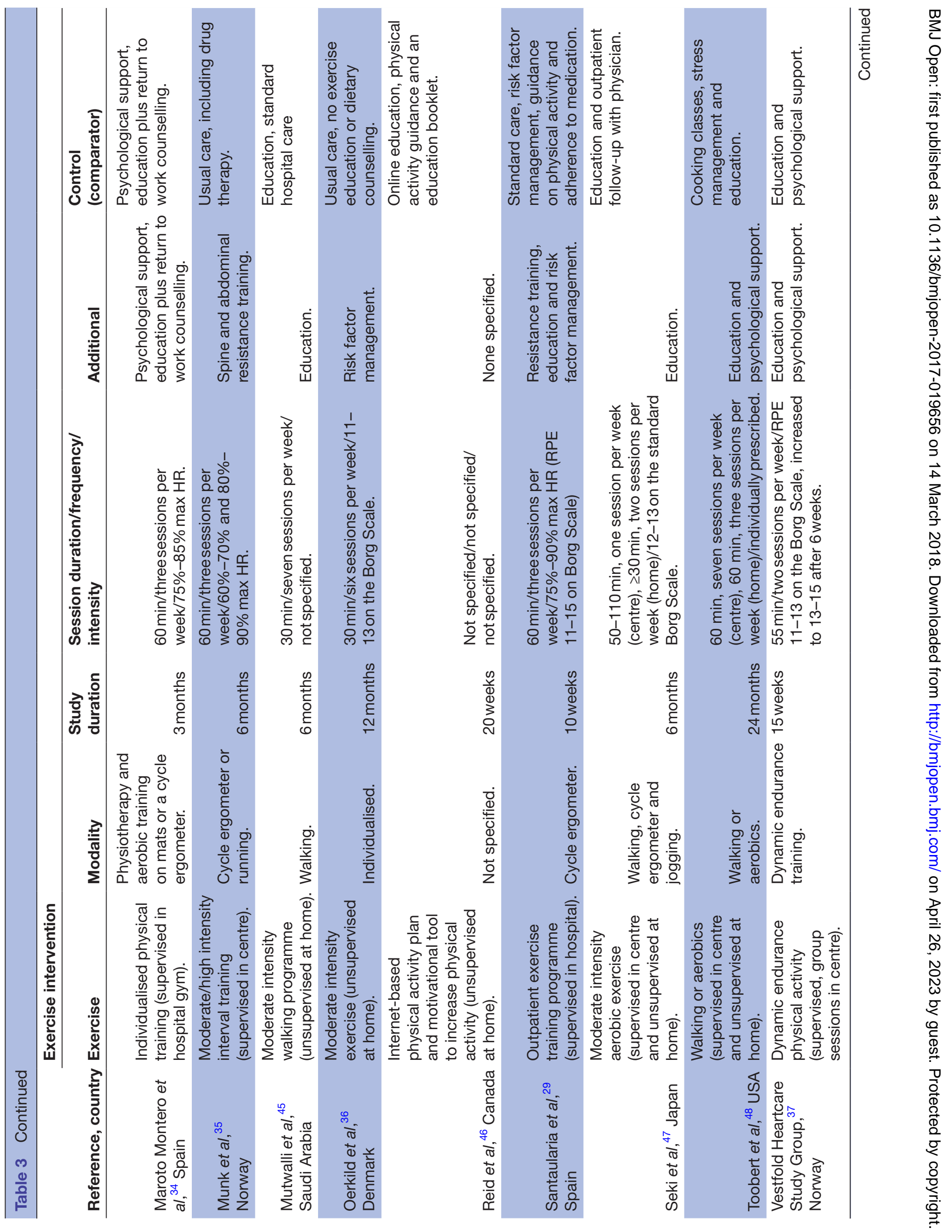




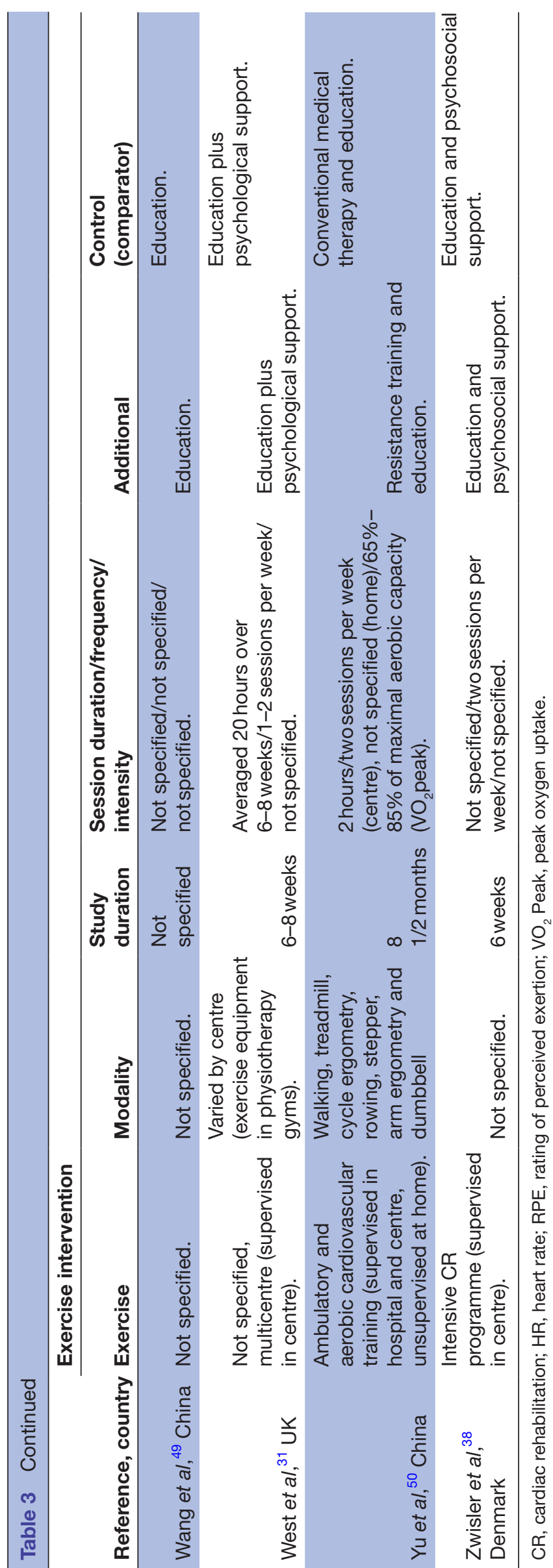

period for all studies included in our review being 24.7 months, it may be that any benefits on mortality will accrue over a longer follow-up. However, the absence of any kind of signal in this review means a substantial longer term benefit is unlikely.

The current analyses do not quite exclude a worthwhile benefit of exercise-based CR on hospital admissions. While a risk difference of $-0.05(95 \%$ CI -0.10 to -0.00$)$ is of borderline statistical significance, it is probably clinically unimportant in the context of no change in all-cause mortality.

From the studies included in this review, we do not know if there is a worthwhile benefit on quality of life, as a meta-analysis was not conducted. However, the authors of the 2016 Cochrane review reported that in 4 of the 22 studies included in this review, there was a significantly higher quality of life in at least half or more of the subscales. ${ }^{32} 454649$

Based on the present data, we are also unable to comment on whether exercise-based CR might be cost-effective. Five of the studies in this review included a within-trial health economic evaluation. ${ }^{3040434450}$ Of these five papers, three studies showed no difference in healthcare costs between groups, ${ }^{404350}$ one found healthcare costs to be lower for exercise-based $\mathrm{CR}^{30}$ and one failed to report a $\mathrm{P}$ value for cost difference. ${ }^{44}$ While a decrease, of borderline statistical significance, in hospital admissions may improve quality of life for patients, it is unclear if this confers any economic benefit, in the absence of robust cost-effectiveness analyses.

It may be that exercise-based CR has an effect on other outcomes, not specifically addressed in this review, such as cardiorespiratory fitness, lifestyle risk factor management, adherence to medication, diet, smoking cessation, psychosocial health and return to work. ${ }^{78657}$ If the focus of future research is on measuring and improving these outcomes, attention will be needed to develop the best multicomponent intervention.

\section{Strengths and limitations}

To our knowledge, this is the first systematic review of exercise-based CR that has pooled data relevant to contemporary medical management of patients diagnosed with coronary artery disease. Although we have not done a de novo quality assessment of 21/22 studies included in this review and instead are relying on a previous Cochrane assessment, it is unlikely that we would have drawn different conclusions from such an assessment. $^{10}$

The current review does not provide information on participant baseline characteristics. In the majority of studies $(20 / 22 ; 91 \%)$, however, baseline characteristics were comparable between the intervention and control groups. ${ }^{10} 29$

While there was no evidence of statistical heterogeneity across trials for all outcome measures ( $\mathrm{P}$ value $<0.01, \mathrm{I}^{2}>30 \%$ ), except for hospital admissions, there was substantial context and interventional 


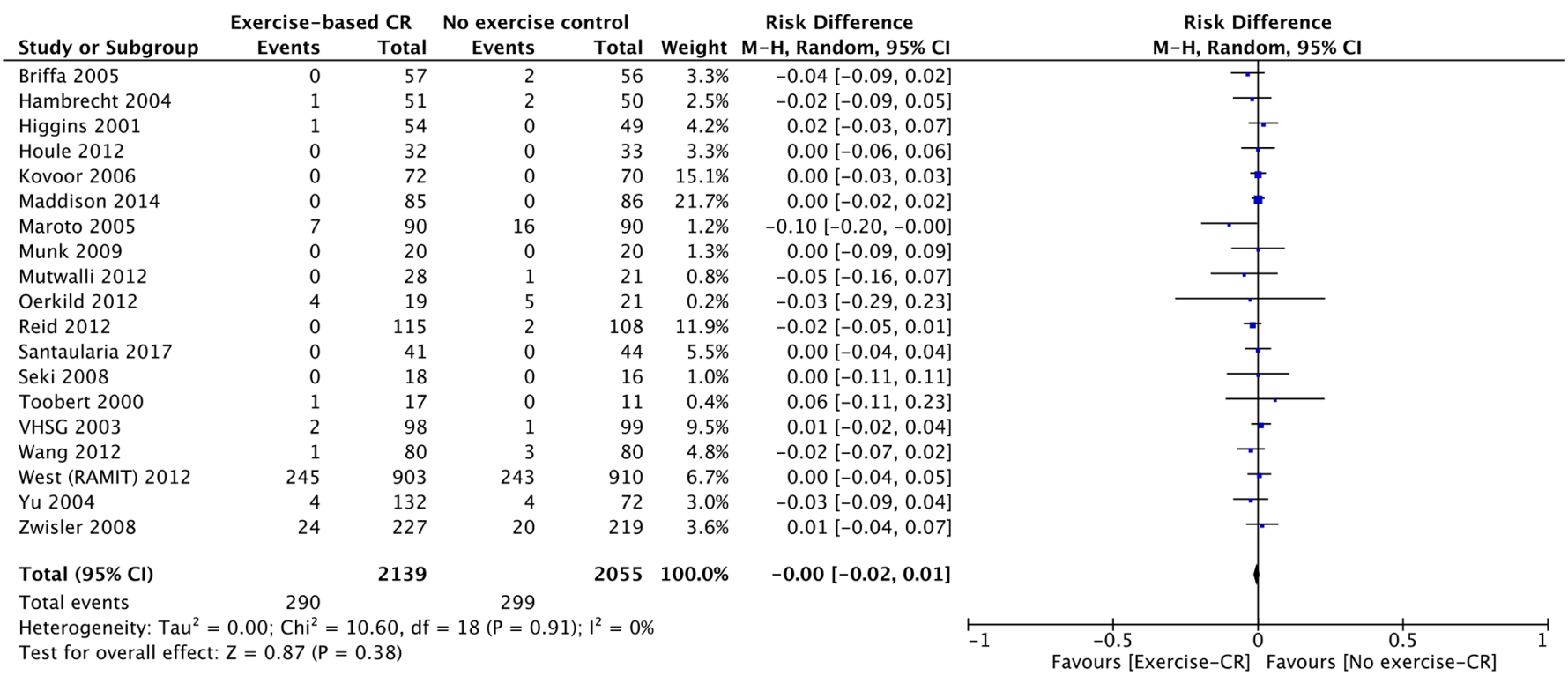

Figure 2 All-cause mortality for studies at their longest follow-up period. Filled squares represent the risk difference for individual studies at the longest reported follow-up. The boxes are proportional to the weight of each study, and the lines represent their $95 \% \mathrm{Cl}$. The filled diamond represents the pooled risk difference. Weights are from random effects analysis. CR, cardiac rehabilitation.

heterogeneity. The studies came from a wide range of clinical environments and countries, and the interventions delivered ranged greatly in quality. When compared with both the BACPR 'minimum standards and core components' ${ }^{8}$ and Association of Chartered Physiotherapists in Cardiac Rehabilitation (ACPICR) guidelines, ${ }^{6}$ there was considerable variation in the exercise interventions delivered (table 3). Critics have questioned the exercise component reported in the largest included study-the RAMIT trial $(\mathrm{n}=1813){ }^{31}$ They argued that underdosage of exercise intensity and duration may have led to the inconclusive result. ${ }^{58}$ Several other studies included in this review also fail to report on the intensity, modality and/or duration of the exercise intervention. Exercise and physical activity has a 'dose-response' relationship with cardiovascular disease risk. ${ }^{59}$ Moreover, a higher exercise capacity $\left(\mathrm{VO}_{2}\right.$ peak) is associated with an improvement in mortality risk. ${ }^{60} 61$ If patients engaging in exercise-based CR do not achieve the correct dose of exercise, a physiological benefit is unlikely. It is a legitimate concern that participants in many included trials may not have received an adequate dose of exercise. In the era of contemporary medical management, higher intensity exercise protocols might be appropriate and effective. ${ }^{62}$

One major concern is the reporting of adherence to, and fidelity of, exercise interventions. ${ }^{10}$ While the majority of studies included in this review report the intended prescription exercise dose $293032-3739404750$ (table 3), it is not possible to determine adherence and fidelity. Without basic reporting of these parameters, the actual exercise dose received cannot be quantified. This may have a significant bearing on intervention efficacy and the results of this meta-analysis. Moving forward, the introduction of checklists and reporting

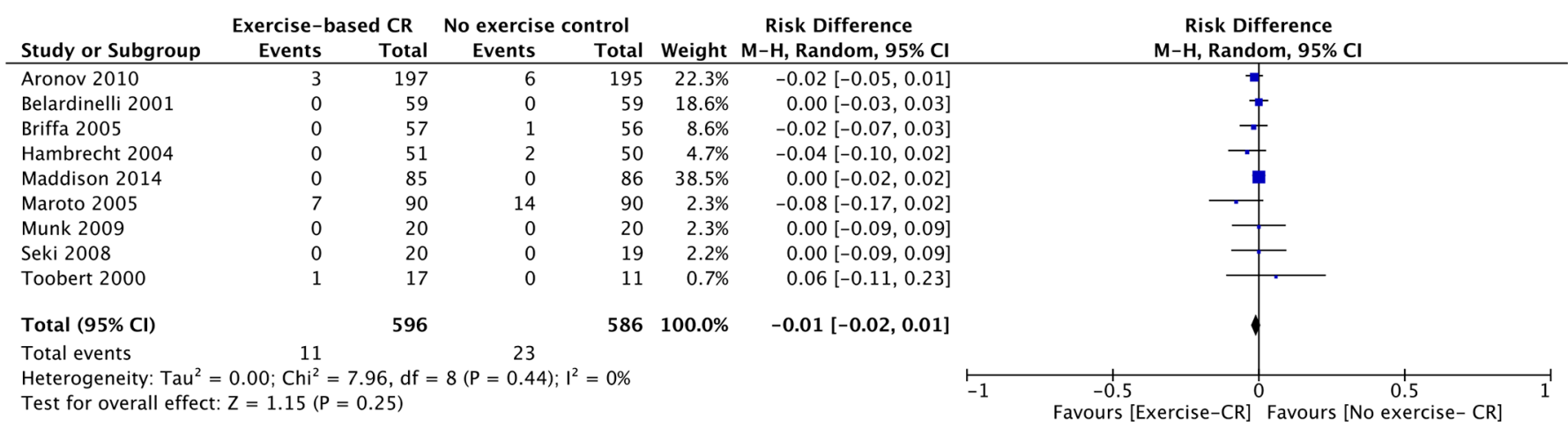

Figure 3 Cardiovascular mortality for studies at their longest follow-up period. Filled squares represent the risk difference for individual studies at the longest reported follow-up. The boxes are proportional to the weight of each study and the lines represent their $95 \% \mathrm{Cl}$. The filled diamond represents the pooled risk difference. Weights are from random effects analysis. CR, cardiac rehabilitation. 


\begin{tabular}{|c|c|c|c|c|c|c|c|c|c|}
\hline Study or Subgroup & \multicolumn{2}{|c|}{ Exercise-based CR } & \multicolumn{2}{|c|}{ No exercise control } & Weight & $\begin{array}{c}\text { Risk Difference } \\
\text { M-H, Random, 95\% Cl }\end{array}$ & \multicolumn{2}{|c|}{$\begin{array}{c}\text { Risk Difference } \\
\text { M-H, Random, 95\% CI }\end{array}$} & \\
\hline Belardinelli 2001 & 11 & 59 & 21 & 59 & $6.1 \%$ & $-0.17[-0.33,-0.01]$ & & & \\
\hline Briffa 2005 & 19 & 57 & 19 & 56 & $5.3 \%$ & $-0.01[-0.18,0.17]$ & & & \\
\hline Giallauria 2008 & 3 & 30 & 7 & 31 & $5.0 \%$ & $-0.13[-0.31,0.06]$ & & - & \\
\hline Hambrecht 2004 & 1 & 51 & 7 & 50 & $9.9 \%$ & $-0.12[-0.22,-0.02]$ & & & \\
\hline Maddison 2014 & 0 & 85 & 0 & 86 & $17.9 \%$ & $0.00[-0.02,0.02]$ & & & \\
\hline Mutwalli 2012 & 4 & 28 & 11 & 21 & $3.0 \%$ & $-0.38[-0.63,-0.13]$ & & & \\
\hline Reid 2012 & 4 & 115 & 6 & 108 & $15.0 \%$ & $-0.02[-0.08,0.03]$ & & & \\
\hline Santaularia 2017 & 4 & 41 & 6 & 44 & $7.4 \%$ & $-0.04[-0.17,0.10]$ & & & \\
\hline VHSG 2003 & 11 & 98 & 14 & 99 & $10.9 \%$ & $-0.03[-0.12,0.06]$ & & - & \\
\hline Yu 2004 & 34 & 132 & 16 & 72 & $8.4 \%$ & $0.04[-0.09,0.16]$ & & & \\
\hline Zwisler 2008 & 95 & 227 & 94 & 219 & $11.0 \%$ & $-0.01[-0.10,0.08]$ & & & \\
\hline Total $(95 \% \mathrm{Cl})$ & & 923 & & 845 & $100.0 \%$ & $-0.05[-0.10,-0.00]$ & & & \\
\hline Total events & 186 & & 201 & & & & & & \\
\hline $\begin{array}{l}\text { Heterogeneity: } \mathrm{Tau}^{2}= \\
\text { Test for overall effect }\end{array}$ & $\begin{array}{l}.00 ; \mathrm{Chi}^{2} \\
=1.97(\mathrm{P}\end{array}$ & $74, d$ & $10(P=0$ & $2=$ & & & $\begin{array}{c}-0.5 \\
\text { Favours [Exercise-CR] }\end{array}$ & Favours [No & $\begin{array}{l}0.5 \\
\text { exercise-CR] }\end{array}$ \\
\hline
\end{tabular}

Figure 4 Hospital admissions for studies at their longest follow-up period. Filled squares represent the risk difference for individual studies at the longest reported follow-up. The boxes are proportional to the weight of each study and the lines represent their $95 \% \mathrm{Cl}$. The filled diamond represents the pooled risk difference. Weights are from random effects analysis. CR, cardiac rehabilitation.

standards of interventional studies should improve reporting quality and trial interpretation. ${ }^{63}$

\section{CONCLUSION}

Based on the outcomes of all-cause mortality and cardiovascular mortality, our analysis indicates conclusively that the current approach to exercise-based CR has no effect when compared with a no-exercise control. There may be a small reduction in hospital admissions following exercise-based CR that is unlikely to be clinically important.

The continued delivery of exercise-based CR needs to be supported by new research to show its impact on health-related quality of life and whether it is a cost-effective intervention.

Contributors RP and MU were principally responsible for the study concept and design. RP and GM were responsible for study selection, data extraction and risk of bias assessment. With the assistance of University Hospital Coventry \& Warwickshire library services, RP updated and ran the searches. RP, MU and PKK were responsible for statistical analysis and interpretation of data. GM and SE provided clinical advice. RP and MU wrote the first draft of the review, and all coauthors contributed to review and editing of drafts of the report. All authors approved the final manuscript. RP is the study guarantor and had full access to all trial level data in the review, takes responsibility for the integrity of the data, and accuracy of the data analysis, and had final responsibility to submit for publication.

Funding This research received no specific grant from any funding agency in the public, commercial or not-for-profit sectors.

Disclaimer This review was not funded, and hence no role was played by funders in the conception, data synthesis, analysis, interpretation or in the drafting of the manuscript.

Competing interests None declared.

Patient consent Not required.

Provenance and peer review Not commissioned; externally peer reviewed.

Data sharing statement № additional data available.

Open Access This is an Open Access article distributed in accordance with the Creative Commons Attribution Non Commercial (CC BY-NC 4.0) license, which permits others to distribute, remix, adapt, build upon this work non-commercially, and license their derivative works on different terms, provided the original work is properly cited and the use is non-commercial. See: http://creativecommons.org/ licenses/by-nc/4.0/ (c) Article author(s) (or their employer(s) unless otherwise stated in the text of the article) 2018. All rights reserved. No commercial use is permitted unless otherwise expressly granted.

\section{REFERENCES}

1. World Health Organisation. Top 10 causes of death worldwide- Fact Sheet. 2017 http://www.who.int/mediacentre/factsheets/fs310/en/ (accessed 29 May 2017).

2. NICE. Myocardial Infarction: cardiac rehabilitation and prevention of further cardiovascular disease. $2013 \mathrm{https} / / /$ www.nice.org uk/guidance/cg172/resources/myocardial-infarction-cardiacrehabilitation-and-prevention-of-further-cardiovascular-disease-pdf35109748874437 (accessed 31 May 2017).

3. BACPR. Cardiovascular disease prevention and rehabilitation. 2012 http://www.bacpr.com/resources/46C BACPR_Standards_and Core_Components_2012.pdf (accessed 31 May 2017).

4. Piepoli MF, Corrà U, Adamopoulos S, et al. Secondary prevention in the clinical management of patients with cardiovascular diseases. Core components, standards and outcome measures for referral and delivery: a policy statement from the cardiac rehabilitation section of the European association for cardiovascular prevention \& rehabilitation. Endorsed by the committee for practice guidelines of the European society of cardiology. Eur J Prev Cardiol 2014;21:664-81.

5. Balady GJ, Williams MA, Ades PA, et al. Core components of cardiac rehabilitation/secondary prevention programs: 2007 update: a scientific statement from the American heart association exercise, cardiac rehabilitation, and prevention committee, the council on clinical cardiology; the councils on cardiovascular nursing, epidemiology and prevention, and nutrition, physical activity, and metabolism; and the American association of cardiovascular and pulmonary rehabilitation. J Cardiopulm Rehabil Prev 2007;27:121-9.

6. ACPICR. Standards for physical activity and exercise in the cardiovascular population. 2015 http://acpicr.com/sites/default/files/ ACPICR Standards 2015.pdf (accessed 31 May 2017).

7. Dalal HM, Doherty P, Taylor RS. Cardiac rehabilitation. BMJ 2015;351:h5000.

8. Buckley JP, Furze G, Doherty P, et al. BACPR scientific statement: British standards and core components for cardiovascular disease prevention and rehabilitation. Heart 2013;99:1069-71.

9. Dalal HM, Zawada A, Jolly K, et al. Home based versus centre based cardiac rehabilitation: cochrane systematic review and metaanalysis. BMJ 2010;340:b5631.

10. Anderson L, Oldridge N, Thompson DR, et al. Exercise-based cardiac rehabilitation for coronary heart disease: cochrane systematic review and meta-analysis. J Am Coll Cardiol 2016;67:1-12.

11. Keeley EC, Boura JA, Grines CL. Primary angioplasty versus intravenous thrombolytic therapy for acute myocardial infarction: a quantitative review of 23 randomised trials. Lancet 2003;361:13-20.

12. D'Souza SP, Mamas MA, Fraser DG, et al. Routine early coronary angioplasty versus ischaemia-guided angioplasty after thrombolysis in acute ST-elevation myocardial infarction: a meta-analysis. Eur Heart J 2011;32:972-82. 
13. Van de Werf F, Ardissino D, Betriu A, et al. Management of acute myocardial infarction in patients presenting with ST-segment elevation. The task force on the management of acute myocardial infarction of the european society of cardiology. Eur Heart $J$ 2003;24:28-66.

14. West RM, Cattle BA, Bouyssie M, et al. Impact of hospital proportion and volume on primary percutaneous coronary intervention performance in England and Wales. Eur Heart J 2011;32:706-11.

15. Anon. Reduction in mortality after myocardial infarction with longterm beta-adrenoceptor blockade. Multicentre international study: supplementary report. Br Med J 1977;2:419-21.

16. Elwood PC, Cochrane AL, Burr ML, et al. A randomized controlled trial of acetyl salicylic acid in the secondary prevention of mortality from myocardial infarction. Br Med J 1974;1:436-40.

17. Anon. Randomised trial of cholesterol lowering in 4444 patients with coronary heart disease: the scandinavian simvastatin survival study (4S). Lancet 1994;344:1383-9.

18. Anon. Indications for ACE inhibitors in the early treatment of acute myocardial infarction: systematic overview of individual data from 100,000 patients in randomized trials. ACE inhibitor myocardial infarction collaborative group. Circulation 1998;97:2202-12.

19. Skinner JS, Minhas R. Commentary on NICE guidance for secondary prevention for patients following a myocardial infarction. Heart 2007;93:864-6.

20. Eisen A, Bhatt DL. Optimal duration of dual antiplatelet therapy after acute coronary syndromes and coronary stenting. Heart 2017;103.

21. Gaziano TA, Bitton A, Anand S, et al. Growing epidemic of coronary heart disease in low- and middle-income countries. Curr Probl Cardiol 2010;35:72-115.

22. Moher D, Liberati A, Tetzlaff J, et al. Preferred reporting items for systematic reviews and meta-analyses: the PRISMA statement. Open Med 2009;3:e123-30.

23. Anon. Acute myocardial infarction: pre-hospital and in-hospital management. The task force on the management of acute myocardial infarction of the European society of cardiology. Eur Heart $J$ 1996;17:43-63

24. Wood DA DP, Poutler N. Joint British recommendations on prevention of coronary heart disease in clinical practice. British cardiac society, British hyperlipidaemia association, British hypertension society, endorsed by the British diabetic association. Heart 1998;80(Suppl 2):S1-29.

25. RevMan. The Nordic Cochrane Centre. The cochrane collaboration, version 5.3 (Review Manager), 2014.

26. Higgins JP, Thompson SG, Deeks JJ, et al. Measuring inconsistency in meta-analyses. BMJ 2003;327:557-60.

27. Higgins JP, Altman DG, Gøtzsche PC, et al. The Cochrane Collaboration's tool for assessing risk of bias in randomised trials. BMJ 2011;343:d5928.

28. Kadda O, Kotanidou A, Manginas A, et al. Lifestyle intervention and one-year prognosis of patients following open heart surgery: a randomised clinical trial. J Clin Nurs 2015;24:1611-21.

29. Santaularia N, Caminal J, Arnau A, et al. The efficacy of a supervised exercise training programme on readmission rates in patients with myocardial ischemia: results from a randomised controlled trial. Eur $J$ Cardiovasc Nurs 2017;16:201-12.

30. Hambrecht R, Walther C, Möbius-Winkler S, et al. Percutaneous coronary angioplasty compared with exercise training in patients with stable coronary artery disease: a randomized trial. Circulation 2004;109:1371-8.

31. West RR, Jones DA, Henderson AH. Rehabilitation after myocardial infarction trial (RAMIT): multi-centre randomised controlled trial of comprehensive cardiac rehabilitation in patients following acute myocardial infarction. Heart 2012;98:637-44.

32. Belardinelli R, Paolini I, Cianci G, et al. Exercise training intervention after coronary angioplasty: the ETICA trial. J Am Coll Cardiol 2001;37:1891-900

33. Giallauria F, Cirillo P, Lucci R, et al. Left ventricular remodelling in patients with moderate systolic dysfunction after myocardial infarction: favourable effects of exercise training and predictive role of $\mathrm{N}$-terminal pro-brain natriuretic peptide. Eur $\mathrm{J}$ Cardiovasc Prev Rehabil 2008;15:113-8.

34. Maroto Montero JM, Artigao Ramírez R, Morales Durán MD, et al [Cardiac rehabilitation in patients with myocardial infarction: a 10year follow-up study]. Rev Esp Cardiol 2005;58:1181-7.

35. Munk PS, Staal EM, Butt N, et al. High-intensity interval training may reduce in-stent restenosis following percutaneous coronary intervention with stent implantation A randomized controlled trial evaluating the relationship to endothelial function and inflammation. Am Heart J 2009;158:734-41.

36. Oerkild B, Frederiksen M, Hansen JF, et al. Home-based cardiac rehabilitation is an attractive alternative to no cardiac rehabilitation for elderly patients with coronary heart disease: results from a randomised clinical trial. BMJ Open 2012;2:e001820.

37. Vestfold Heartcare Study Group. Influence on lifestyle measures and five-year coronary risk by a comprehensive lifestyle intervention programme in patients with coronary heart disease. Eur $J$ Cardiovasc Prev Rehabil 2003;10:429-37.

38. Zwisler AD, Soja AM, Rasmussen S, et al. Hospital-based comprehensive cardiac rehabilitation versus usual care among patients with congestive heart failure, ischemic heart disease, or high risk of ischemic heart disease: 12-month results of a randomized clinical trial. Am Heart J 2008;155:1106-13.

39. Aronov DM, Krasnitskiı̄ VB, Bubnova MG, et al. [Physical training at ambulatory-polyclinical stage in complex rehabilitation and secondary prevention of patients with ischemic heart disease after acute incidents. Effect on physical working capacity, hemodynamics, blood lipids, clinical course and prognosis (Russian cooperative study)]. Kardiologiia 2009;49:49-56.

40. Briffa TG, Eckermann SD, Griffiths AD, et al. Cost-effectiveness of rehabilitation after an acute coronary event: a randomised controlled trial. Med J Aust 2005;183:450-5.

41. Higgins HC, Hayes RL, McKenna KT. Rehabilitation outcomes following percutaneous coronary interventions (PCI). Patient Educ Couns 2001:43:219-30.

42. Houle J, Doyon O, Vadeboncoeur N, et al. Effectiveness of a pedometer-based program using a socio-cognitive intervention on physical activity and quality of life in a setting of cardiac rehabilitation. Can J Cardiol 2012;28:27-32.

43. Kovoor P, Lee AK, Carrozzi F, et al. Return to full normal activities including work at two weeks after acute myocardial infarction. $A m \mathrm{~J}$ Cardiol 2006;97:952-8.

44. Maddison R, Pfaeffli L, Whittaker R, et al. A mobile phone intervention increases physical activity in people with cardiovascular disease: results from the HEART randomized controlled trial. Eur $J$ Prev Cardiol 2015;22:701-9.

45. Mutwalli HA, Fallows SJ, Arnous AA, et al. Randomized controlled evaluation shows the effectiveness of a home-based cardiac rehabilitation program. Saudi Med J 2012;33:152-9.

46. Reid RD, Morrin LI, Beaton LJ, et al. Randomized trial of an internet-based computer-tailored expert system for physical activity in patients with heart disease. Eur J Prev Cardiol 2012:19:1357-64.

47. Seki E, Watanabe Y, Shimada K, et al. Effects of a phase III cardiac rehabilitation program on physical status and lipid profiles in elderly patients with coronary artery disease: Juntendo Cardiac Rehabilitation Program (J-CARP). Circ J 2008;72:1230-4.

48. Toobert DJ, Glasgow RE, Radcliffe JL. Physiologic and related behavioral outcomes from the Women's Lifestyle Heart Trial. Ann Behav Med 2000;22:1-9.

49. Wang W, Chair SY, Thompson DR, et al. Effects of home-based rehabilitation on health-related quality of life and psychological status in Chinese patients recovering from acute myocardial infarction. Heart Lung 2012;41:15-25.

50. Yu CM, Lau CP, Chau J, et al. A short course of cardiac rehabilitation program is highly cost effective in improving long-term quality of life in patients with recent myocardial infarction or percutaneous coronary intervention. Arch Phys Med Rehabil 2004;85:1915-22.

51. Toobert DJ, Strycker LA, Glasgow RE. Lifestyle change in women with coronary heart disease: what do we know? J Womens Health 1998;7:685-99.

52. Jolliffe JA, Rees K, Taylor RS, et al. Exercise-based rehabilitation for coronary heart disease. Cochrane Database Syst Rev 2001:1:CD001800.

53. Heran BS, Chen JM, Ebrahim S, et al. Exercise-based cardiac rehabilitation for coronary heart disease. Cochrane Database Syst Rev 2011:CD001800.

54. Wilhelmsen L, Sanne H, Elmfeldt D, et al. A controlled trial of physical training after myocardial infarction. Effects on risk factors, nonfatal reinfarction, and death. Prev Med 1975;4:491-508.

55. van Halewijn G, Deckers J, Tay HY, et al. Lessons from contemporary trials of cardiovascular prevention and rehabilitation: a systematic review and meta-analysis. Int J Cardiol 2017;232:294-303.

56. Valkeinen $\mathrm{H}$, Aaltonen $\mathrm{S}$, Kujala UM. Effects of exercise training on oxygen uptake in coronary heart disease: a systematic review and meta-analysis. Scand J Med Sci Sports 2010;20:545-55.

57. Yohannes AM, Doherty P, Bundy C, et al. The long-term benefits of cardiac rehabilitation on depression, anxiety, physical activity and quality of life. J Clin Nurs 2010;19:2806-13.

58. Conraads VM, Denollet J, De Maeyer C, et al. Exercise training as an essential component of cardiac rehabilitation. Heart 2012;98:674-5. author reply 5 . 
59. Sattelmair J, Pertman J, Ding EL, et al. Dose response between physical activity and risk of coronary heart disease: a meta-analysis. Circulation 2011;124:789-95.

60. Kodama S, Saito K, Tanaka S, et al. Cardiorespiratory fitness as a quantitative predictor of all-cause mortality and cardiovascular events in healthy men and women: a meta-analysis. JAMA 2009;301:2024-35.

61. Garber CE, Blissmer B, Deschenes MR, et al. American college of sports medicine position stand. Quantity and quality of exercise for developing and maintaining cardiorespiratory, musculoskeletal, and neuromotor fitness in apparently healthy adults: guidance for prescribing exercise. Med Sci Sports Exerc 2011;43:1334-59.

62. McGregor G, Nichols S, Hamborg T, et al. High-intensity interval training versus moderate-intensity steady-state training in UK cardiac rehabilitation programmes (HIIT or MISS UK): study protocol for a multicentre randomised controlled trial and economic evaluation. BMJ Open 2016;6:e012843.

63. Slade SC, Dionne CE, Underwood M, et al. Consensus on Exercise Reporting Template (CERT): modified delphi study. Phys Ther 2016;96:1514-24. 
Correction: Is exercise-based cardiac rehabilitation effective?

A systematic review and meta-analysis to re-examine

\section{the evidence}

Powell R, McGregor G, Ennis S, et al. Is exercise-based cardiac rehabilitation effective? A systematic review and meta-analysis to re-examine the evidence. BMJ Open 2018;8:e19656. doi: 10.1136/bmjopen-2017-019656.

The author was unaware of a protocol paper that changes a couple of things in this paper. It does not change the conclusions.

In Table 1, the 'Intention-to treat analysis conducted' is currently listed as 'High risk' but should read 'Low risk'. The 'Support for judgement' column for this row should read 'Outcomes will be analysed on an intention-to-treat basis.'

In Table 2, in the 'Santaularia et al, ${ }^{29}$ Spain' row, the 'Recruitment period (years)' currently reads 'None specified' but this should read '2010-2012'.

Open Access This is an Open Access article distributed in accordance with the Creative Commons Attribution Non Commercial (CC BY-NC 4.0) license, which permits others to distribute, remix, adapt, build upon this work non-commercially, and license their derivative works on different terms, provided the original work is properly cited and the use is non-commercial. See: http://creativecommons.org/licenses/by-nc/4.0/

C Article author(s) (or their employer(s) unless otherwise stated in the text of the article) 2018. All rights reserved. No commercial use is permitted unless otherwise expressly granted.

BMJ Open 2018;8:e019656corr1. doi:10.1136/bmjopen-2017-019656corr1

Check for updates 